\section{Auf der sicheren Seite}

\section{Kolumne Für viele ist die neue Datenschutzgrundverordnung - kurz DSGVO - schon jetzt das Unwort des Jahres. Michael Schiewack tickt da ein wenig anders. Er widmet sich der Neuerung mit voller Hingabe.}

In meiner Praxis ist es dunkel. Die Fenster haben wir mit blickdichter Folie beklebt und die Wände schallschutzisoliert. Ich überlasse nichts dem Zufall. Schließlich gehöre ich nicht zu den Kollegen, denen alles egal ist. In meiner Praxis sind alle sicher: meine Klienten und vor allem: ihre Daten.

Erst heute Morgen kommt eine Neuaufnahme in die Praxis und legt los: „Hallo! Ich möchte einen Termin bei Ihnen. Hier ist mein Rezept, ich habe nämlich schon seit Wochen so ein ..." Noch bevor die Person ihren Satz beenden kann, grätsche ich ihr gekonnt ins Wort. Ich lege meinen Zeigefinger vor die geschürzten Lippen und hauche: „EU-DSGVO.“ Sie schaut mich fassungslos an. Diesen Gesichtsausdruck kenne ich nun schon und hauche weiter: „Datenschutzrichtlinie! Ich will Sie nur schützen." Freundlich nicke ich in den halb besetzten Wartebereich. Der männliche Klient mit Kapuzenpulli, Sonnenbrille und Wollmütze schaut kurz hinter seinem Magazin hoch.

Der Neuaufnahme reiche ich einen braunen Briefumschlag und bitte sie, ihr Rezept dort hineinzustecken. Im Gegenzug bekommt sie 20 Seiten Aufklärungsformulare von mir. Ich tippe ihre Daten in meinen Computer, sie liest und meint so etwas wie: „Muss das alles wirklich so sein?" Ich bestätige, sie unterschreibt. „Geschieht ja alles nur zu Ihrem Besten“, schiebe ich nach, „die europäischen Verantwortungs-

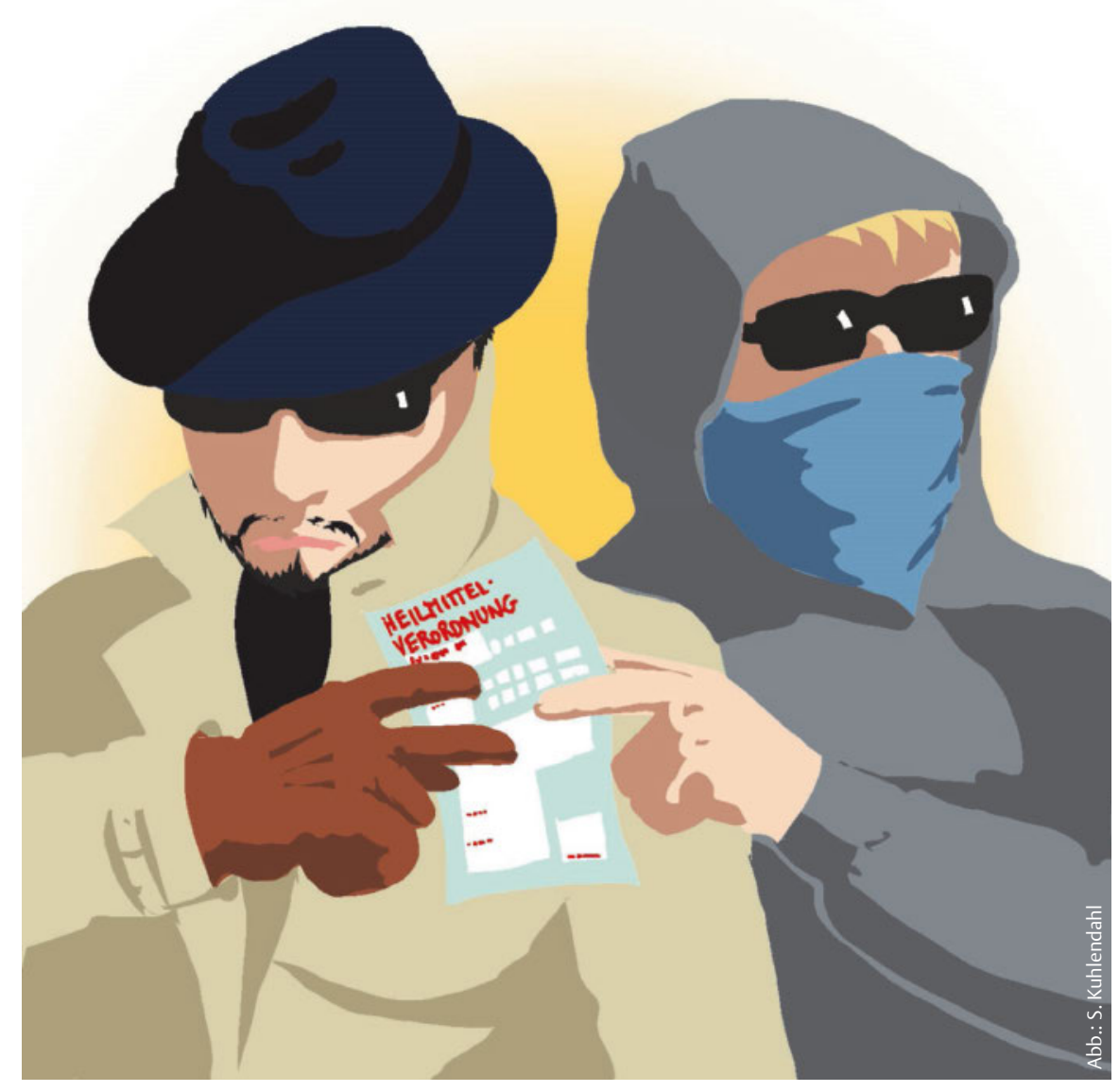

träger haben schließlich nur das Wohl der Bürger und den Schutz ihrer Daten im Sinn.“

Wer lässt sich schon von so einem bisschen Papierkram abschrecken? Ich habe schließlich auch keine Kosten und Mühen gescheut, alles zu vertuschen, was meine Klienten in Erklärungsnot bringen könnte. Zum Beispiel habe ich über eine Firma, die was von meinen Sorgen versteht, einen KlientenNummern-Generator erstanden. Hat mich nur ein kleines Vermögen gekostet. Dafür ist das Ganze sogar zertifiziert. Die Neuaufnahme bekommt nun eine Nummer ausgedruckt, die sie sich innerhalb der nächsten zehn Minuten merken soll, bevor das Papier sich selbst zerstört. Der Zufall hat hier nichts mehr zu sagen.

Nach dieser Prozedur bin ich erleichtert, sie künftig mit „Frau 20-35-A“ ansprechen zu können. Ich überreiche ihr einen braunen Umschlag mit den nächsten Terminen. Und ich verweise darauf, dass sie möglichst niemandem erzählen soll, dass sie in meine Praxis kommt. Auch ich werde mich, wie schon seit Jahren und nun ganz besonders, an die Schweigepflicht halten. Die weiteren Termine werden wir „zufällig“ an einem öffentlichen Ort absprechen. Absagen werden nur noch von einer Brieftaube oder
5

Terminabsagen sind nur noch per Brieftaube gestattet. der Post-Eule entgegengenommen. Zudem bitte ich sie, künftig neutral gekleidet zu erscheinen. Schwarz sei das Unverfänglichste. So könne sie sicher sein, ihre persönlichen Rechte zu wahren. Frau 20-35-A verspricht, alles so zu tun, und verabschiedet sich wortlos.

Ich bin sehr froh, die neuen Richtlinien zum Schutze meiner Klienten konzeptionell voll und umfänglich erfasst zu haben. Ich garantiere ihnen nun, dass niemand von mir und meiner Einrichtung weiß und dass auch niemand erfährt, wie erfolgreich wir unseren Klienten helfen können.

Michael Schiewack 